\title{
Use Angle and Motional Direction of End Scrapers: $A$ Case Study of the Palaeolithic in Hokkaido, Japan
}

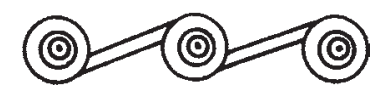

\author{
KATSUNORI TAKASE
}

INTRODUCTION

END SCRAPERS ARE ONE OF THE ESSENTIAL ARTIFACTS in human prehistory studied by archaeologists not only in Japan, but elsewhere in the world. Because these artifacts are highly conducive to stylistic embellishments, they provide significant clues for chronological investigation and study of the relationships between sites. The highly curated aspects of end scrapers as a tool also offer valuable information about reduction sequences and functional systems of stone tools (Barnes 1932; Shott 1995; Siegel 1984). Furthermore, this tool is often associated with fur/hide resource processing, clothing which is indispensable for humans, especially in mid- and high-latitude zones. The function-specific character of end scrapers makes it easier for us to examine issues related to the history of technology, the division of labor, gender, social stratification and the symbolism of power (Frink and Weedman 2005; Hayden 1979, 1990, 1993; Semenov 1964).

In studies of the Palaeolithic in the Japanese Islands, end scrapers have played an important role not only in chronology, but also in discussions identifying human groups and their adaptation to cold climates. Arguments in the past concerning cultural attributions and adaptive strategies were not necessarily backed up by sufficient evidence on the use and functions of end scrapers. However, in the last decade, lithic use-wear analysis has demonstrated that the Palaeolithic end scraper was one of the principal tools for hide-working (Kanomata 2003, 2004, 2008; Takase 2003, 2008b; Tsutsumi 1997a, 1997b, 1999, 2000).

Nevertheless, very few attempts have been made to investigate in detail the specific mechanics of how end scrapers were used. For example, little is known about the direction of tool movement and the hafting method, although these provide basic information for discussing the technology of hide processing and the tool use strategies of hide-workers. The objective of this article is to demonstrate a method for estimating the direction of tool movement of end scrapers, focusing specifically on the relationship between the use angle and the edge angle (Fig. 1). 


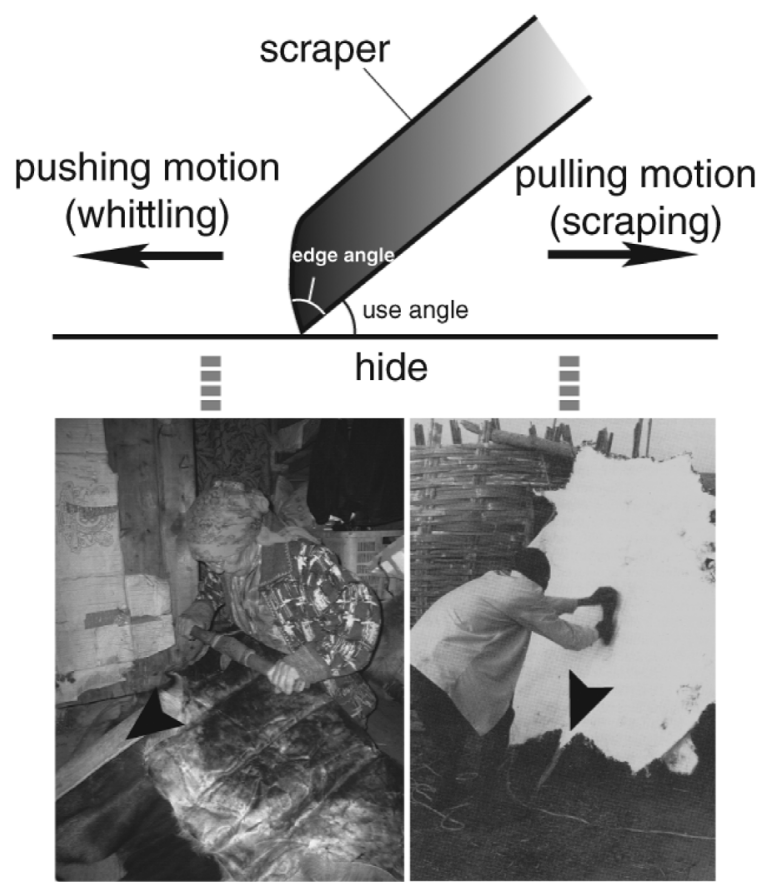

Fig. 1. The direction of tool movement of end scraper. Lower left photograph: Even women in central Kamchatka, processing hide using a scraper in a pushing motion; lower right photograph: a Chawa tanner in Ethiopia scraping hide in a pulling motion (after Clark and Kurashina 1981).

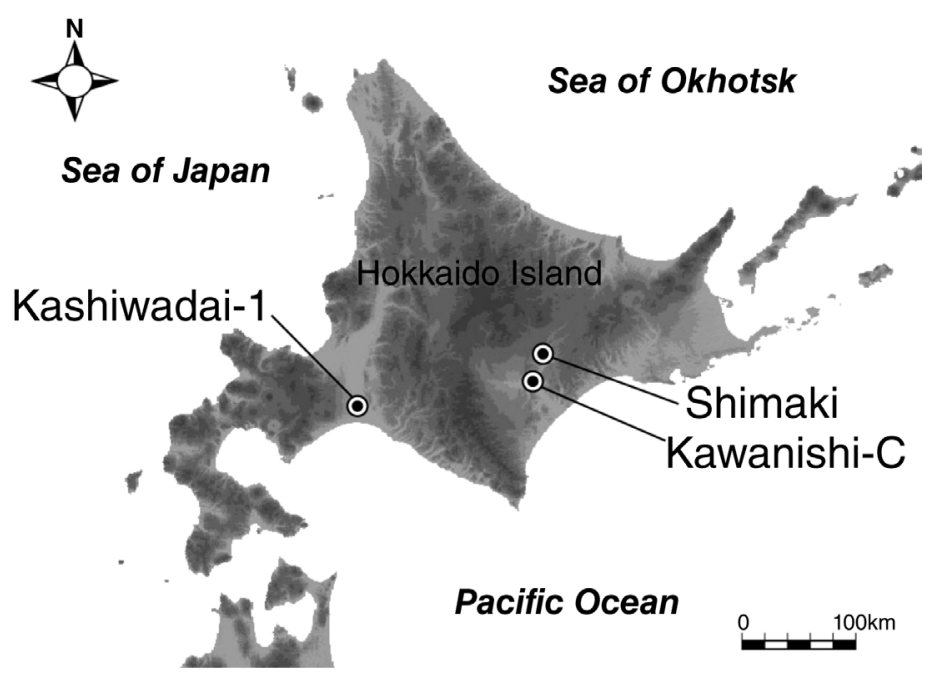

Fig. 2. Map showing location of sites.

\section{SPECIMENS ANALYZED}

The database for the present study consists of end scrapers from three late Palaeolithic sites in central and eastern Hokkaido Island: Shimaki (Kato and Yamada 1988), Kashiwadai-1 (Loc. B, Fukui and Koshida 1999), and Kawanishi-C (Pre-pottery II phase, Kitazawa et al. 1998) (Fig. 2). The ratio of end scrapers in each assemblage of 
flaked stone tools omitting blade, flake and chip tends to be high (about 25-75\%), so therefore end scrapers are one of the most representative tools of the period (Table 1).

Since the 1970s, lithic assemblages characterized by unstandardized tool forms and a high frequency of end scrapers have been thought to be the oldest component in prehistoric Hokkaido (e.g., Education Board of Chitose City 1974; Tsuji 1973). This perspective has been supported by materials found under the En-a tephra layer (c. 19,000 to 21,000 B.P.) in the 1990s (Fukui and Koshida 1999; Kitazawa et al. 1995, 1998). According to recent chronological studies, they should be regarded as artifacts assigned to the first half of the late Palaeolithic in Hokkaido (Izuho and Akai 2005; Terasaki 2006; Yamada 2006). Radiocarbon dates of charred material from the cultural layer at Shimaki is 23,800 B.P. (Kato and Yamada 1988), and 21,420 \pm 190 B.P. and 21,800 \pm 90 B.P. at Kawanishi-C (Kitazawa et al. 1998). In Kashiwadai, 30 results of AMS dating of charred material collected from layers under the En-a tephra show dates ranging from $37,350 \pm 550$ B.P. to $18,840 \pm 150$ B.P. (Fukui and Koshida 1999). They are consistent with the recognized date of the En-a tephra layer and there is still no reliable lithic assemblage older in Hokkaido. As far as the purpose of this study is concerned, it is not necessary to investigate a detailed chronology. Therefore, the present article will be based on the assumption that all specimens from the three sites belong to the same chronological phase (i.e., the first half of the late Palaeolithic).

The end scrapers from these sites number about 400. The common technomorphological characteristics are unifacial flaking, a convex bit in plan view, and a plano-convex lateral section. Almost all of the artifacts are made from obsidian and hard shale.

End scrapers from Kashiwadai-1 and Shimaki tend to be made on relatively small, short, and round-shaped flakes (Fig. 3:1-18). In contrast, a lot of end scrapers made on blades and on relatively long flakes are included in the materials from Kawanishi-C (Fig. 3:19-22). It is also noteworthy that concentrations of microblade and nonmicroblade industries have a different spatial distribution in Kashiwadai-1.

\section{METHODS AND RESULTS OF ANALYSES}

The first step of the study was to choose end scrapers with heavy edge abrasion that is visible to the unaided eye. Then, use-wear analysis by the "high-power approach" (Keeley 1977, 1980) was performed using an incident light microscope (OLYMPUS $\mathrm{BX}-30 \mathrm{M}$ ) with a magnification from $100 \mathrm{x}$ to $500 \mathrm{x}$ to ensure that these tools were used for hide-working.

As a result of observation by the naked eye, it was clear that 34 end scrapers (about $8 \%$ of the total specimens) had severe abrasions on their working edges. Thirty-three of them had typical "dry-hide/leather polish" (Keeley 1980) or "E2 type polish" (Akoshima 1989; Kajiwara and Akoshima 1981). On these specimens, striations perpendicular to the edge were observed with the use-wear polish without exception (Fig. 4). Results of use-wear analysis strongly suggest that the end scrapers were used for hide-working. One specimen with "bone polish" was not considered in this article.

The problem that we have to consider next is the use angle of the 33 specimens with the dry-hide/leather polish. The use angle is the tool inclination against the hide surface when a scraper is in use. In the case of a unifacial end scraper, it can be evaluated by measuring an angle formed by the ventral face and the abrasive wear surface. 


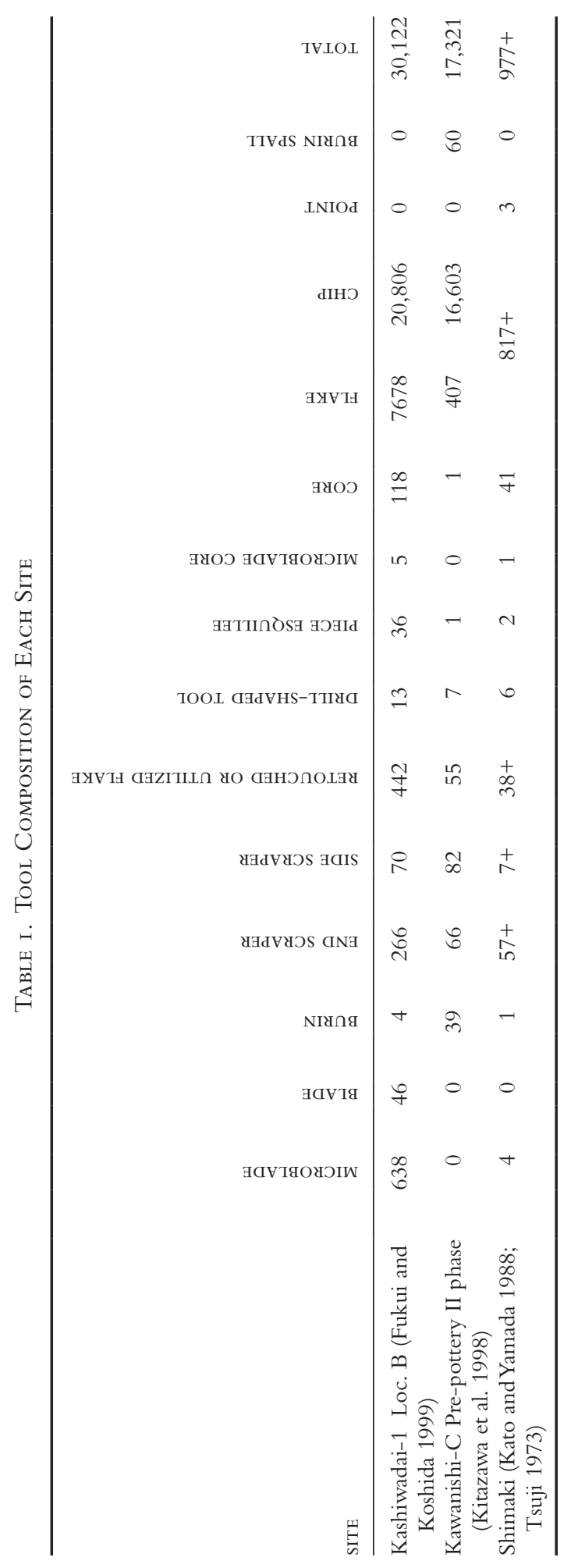



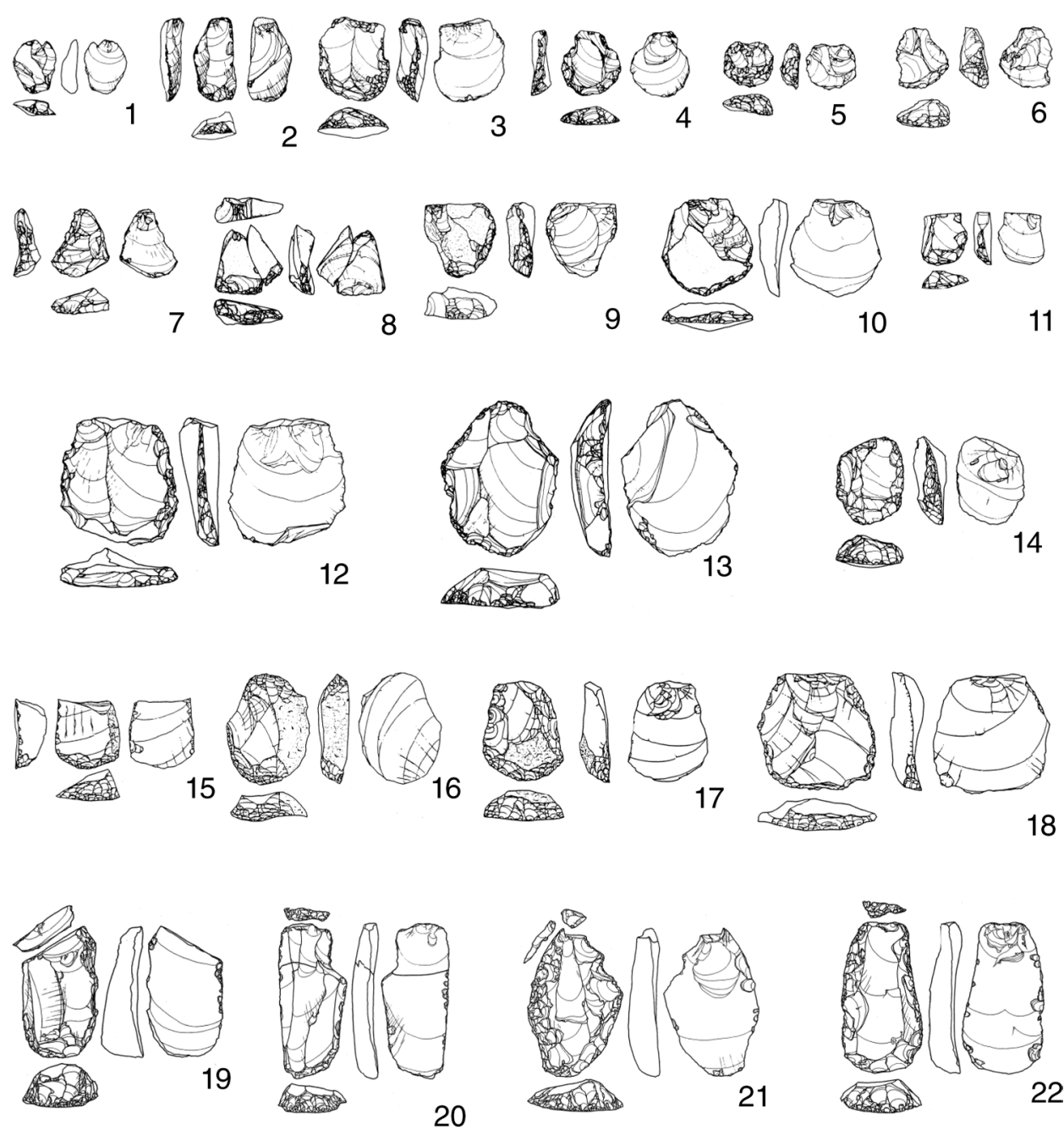

0

$10 \mathrm{~cm}$

Fig. 3. End scrapers of the first half of the late Palaeolithic in Hokkaido (1-14: Kashiwadai-1; 15-18: Shimaki; 19-22: Kawanishi-C).

The replication method is appropriate to measure the use angle accurately. After the working edges of the specimens were replicated with silicone-rubber impression material made for dentistry ("Tokuso Fit Tester," Tokuyama Dental Co. Ltd., Japan) (Fig. 5), the replicas were sliced vertically with a razor blade. In order to slice replicas in a suitable position for measuring the use angle, before putting the silicone on the stone tools, it can be effective to use an extremely soft graphite pencil (e.g., 9B) to dot a minute point on the tip of the ventral face with the most severe abrasion. A point created by the black particles will be copied to the inside of the replicas; this will be the mark to cut (however, a graphite pencil is not used in Figure 5). The sliced replicas were observed with a stereoscope (OLYMPUS SZX-7) at the magnification of 


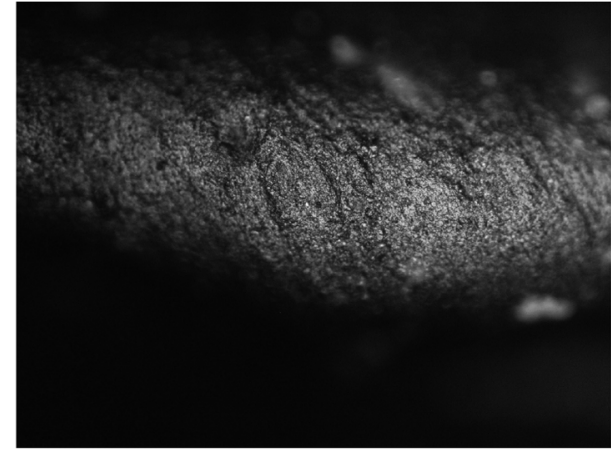

1 Kashiwadai-1 No. 180 (100 x)

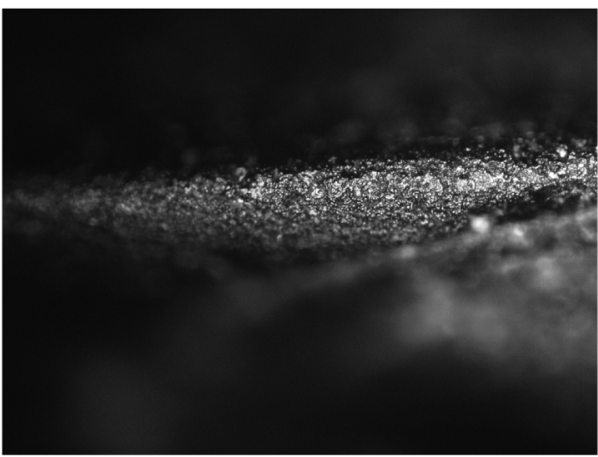

3 Kashiwadai-1 No. 107 (100 x)

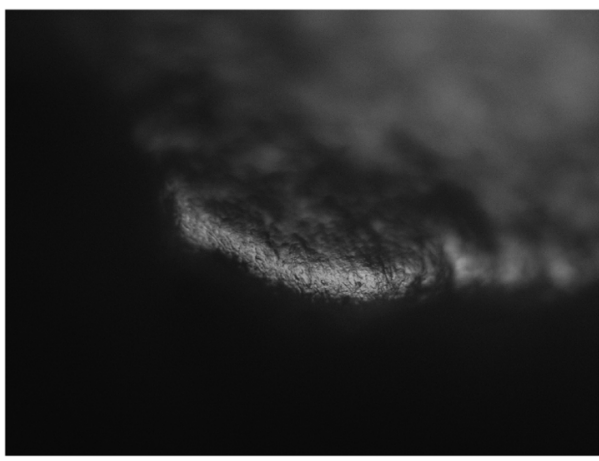

5 Kashiwadai-1 No. 242 (100 x)

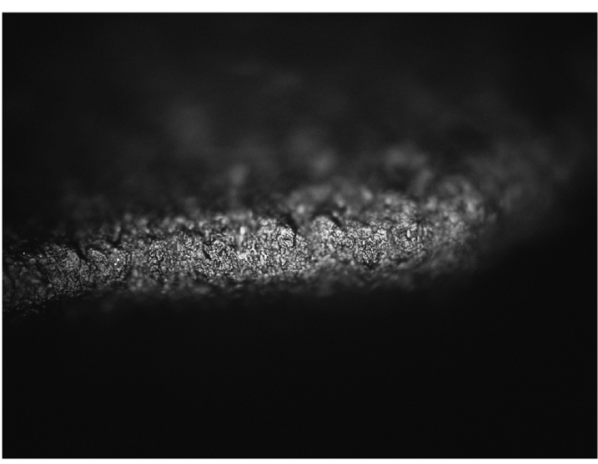

7 Shimaki SK87.J22.5 (100 x)

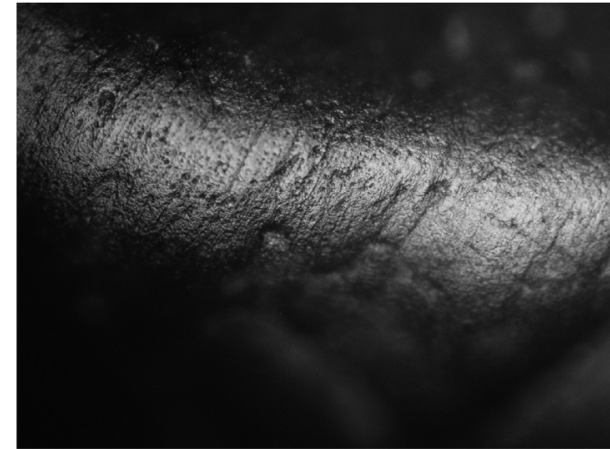

2 Kashiwadai-1 No. 196 (100 x)

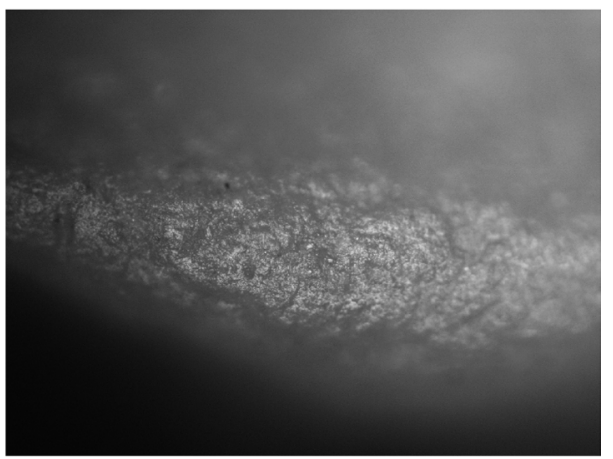

4 Kashiwadai-1 No. 164 (100 x)

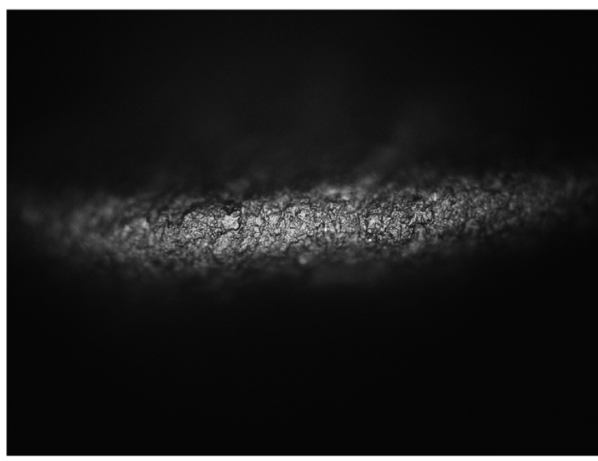

6 Shimaki SK89.B13.27 (100 x)

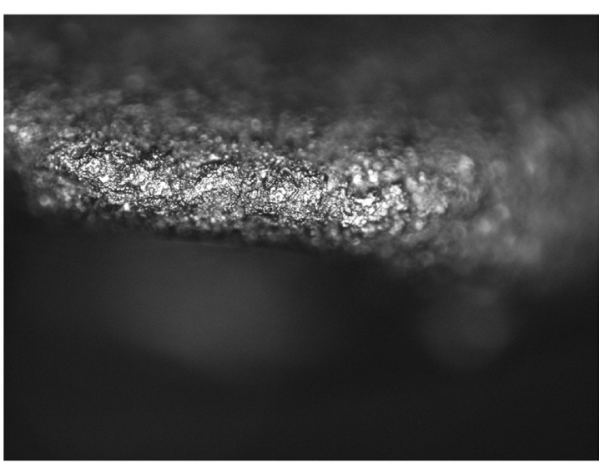

8 Kawanishi-C Fig. 16-2 (100 x)

Fig. 4. Micrographs of use-wear polish on end scrapers (width of photograph: $600 \mu$ ). 

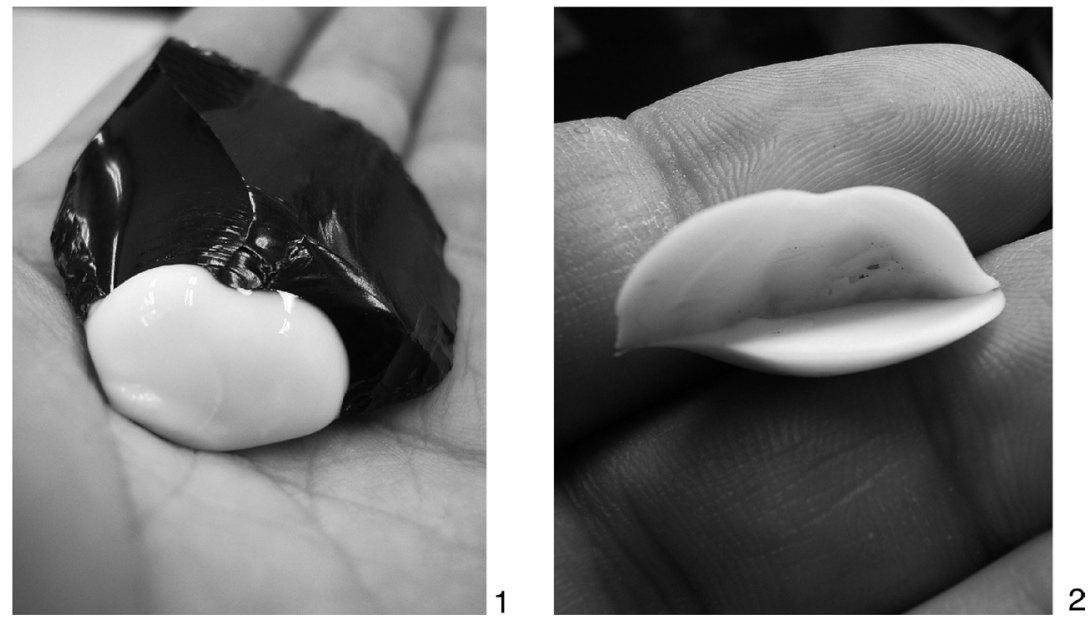

Fig. 5. Replicating the edge of an end scraper using silicone-rubber (1) and its inside view (2).

$40 \mathrm{x}-80 \mathrm{x}$. Graphite particles that remain on stone tools can be easily removed by using a kneaded eraser.

Clay might be used as an option to create replicas using a technique that Burgess and Kvamme (1978) introduced to measure the edge angle. However, clay is not necessarily suitable mold material for measuring the edge angle, because it often causes accidental errors due to deformation. In addition, it is difficult to convey clay replicas preserving their shape in field and on-site investigation (e.g., ethnoarchaeological survey and research overseas). In case of accurately measuring the edge angle at higher magnification, such a risk of mold modification should be reduced.

On the other hand, silicone is a highly reproducible material for observing the surface of stone tools as d'Ericco (1988) demonstrated. Furthermore, it has excellent properties to preserve its shape and moderate flexibility, although it is fluid enough to make replicas of various forms of stone tools before it becomes indurated. It does not damage fine stone such as obsidian; in the case of course-textured stone, mold lubricant (e.g., 5-7 wt $\%$ Palaroid B72 acetone fluid) enables protection of the surface of the specimen.

Figure 6 shows a cross section of replicated working edges. In the case of the specimen shown in Figure 6-1, the use angle is between $62^{\circ}$ and $74^{\circ}$, and the mean angle is $68^{\circ}$. Such a replica method is more effective to accurately measure the use angle than observing the working edge sideways directly with a stereoscope. The abrasive wear surface has a tendency to be relatively stable and flat, regardless of the period. In most cases, the difference between the two extreme values of the use angle is less than $25^{\circ}$. Mean value of the use angle is shown in Table 2. The mean edge angle was obtained by values measured on five points in the working edge with a protractor.

\section{DISCUSSION}

The motional direction of an end scraper is divided into two categories: a "pushing motion" and a "pulling motion" as shown in Figure 1. The former is called "whit- 


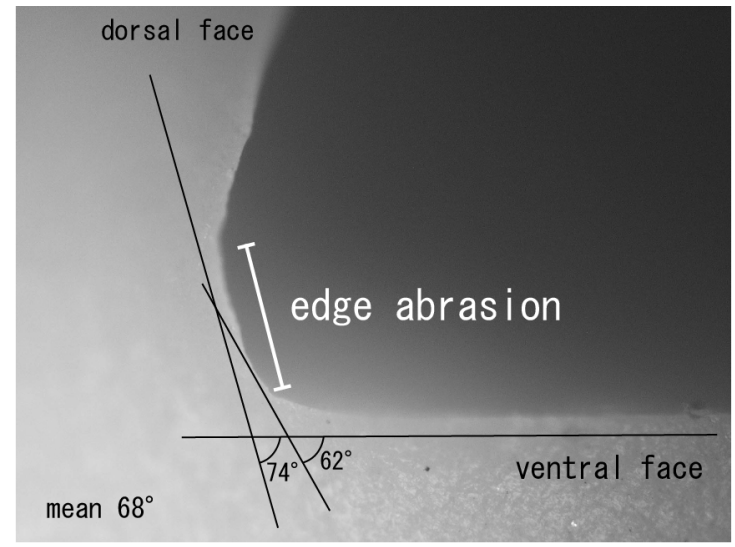

1

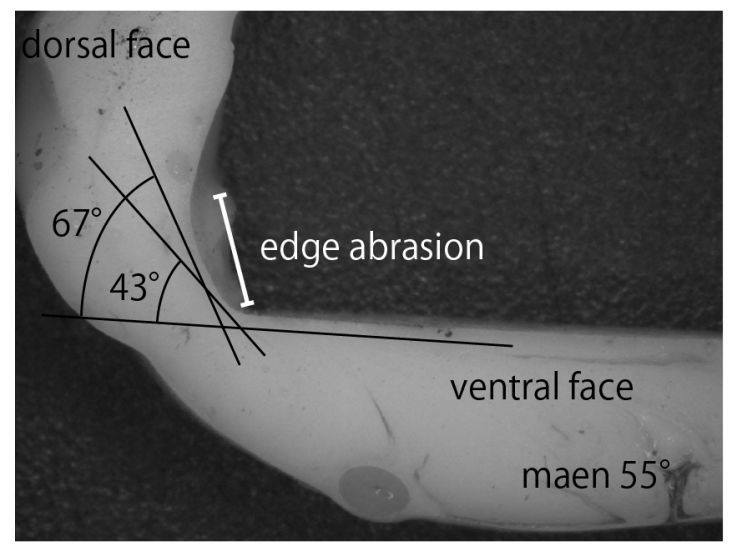

Fig. 6. Cross section of a replica (1: Kashiwadai-1, No. 34; 2: Kashiwadai-1, No. 196).

tling," and the latter is known as "scraping" in the terminology of experimental archaeology. Generally, the morphological features of end scrapers require a smaller use angle in the case of a pushing motion, while the use angle tends to be larger when the end scraper is used in a pulling motion. Experimental archaeology has revealed that a pushing motion produces a higher frequency of micro-flaking and more distinctive striation on the ventral face than on the dorsal face (Barnes 1932:52-53; Odell 1981 : 202-203).

According to ethnographic sources for Northeast Asia, the average use angle is $34^{\circ}$ when an end scraper is used in a pushing motion (Bogoras 1904-1909; Jochelson 1908; Takase 2004). The use angle of scrapers with crooked and straight hafts used in a pushing motion in Alaska and Arctic Canada is less than 45 (Murdoch 1893:294295; Nelson 1899: Pl. XLIX). Some micro-flakings can be seen on the ventral face of these ethnographic materials (Nissen and Dittemore 1974:70). However, results of experimental archaeology have showed that micro-flakings are not often formed through tanning (Tringham et al. 1974:189), because animal hide is not a very hard material. In addition, the author also confirmed that the number of micro-flakings on 


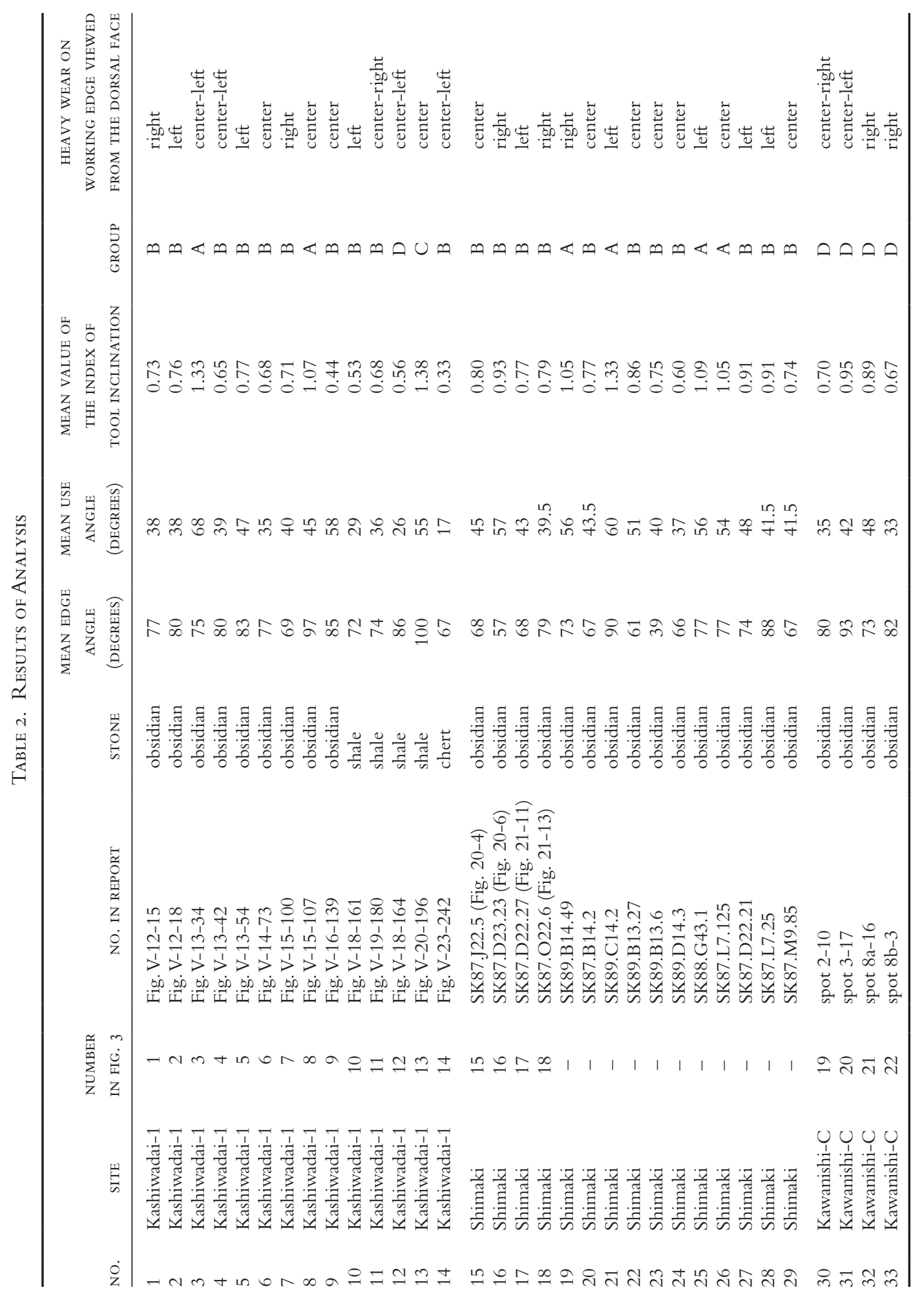


ethnographic stone scrapers used in the Kamchatka Peninsula and Alaska is very small, even if a tanner keeps using these tools for a long time until severe abrasive wear is formed on the edge. Therefore, the lack of micro-flaking on the ventral face does not necessarily suggest that the end scraper was not used in a pushing motion.

In a pulling motion, micro-flaking and striation is more remarkable on the dorsal face than the ventral face (Barnes 1932:52-53; Clarke and Kurashina 1981:312; Odell 1981:200-201; Semenov 1964:88; Tringham et al. 1974:189, 191; Wilmsen 1968 : 159). The use angle is $70^{\circ}-90^{\circ}$ in ethnographic records in Ethiopia, where end scrapers are used only in a pulling motion (Brandt 1997:735-736; Brandt and Weedman 1997:353; Brandt et al. 1996:40; Gallagher 1974:177-181, 1977:411; Weedman $2002: 734)$. However, tanning in a pushing motion does not always produce a lot of micro-flakings on the dorsal face, because the hide is not so hard as to generate a consistent amount of micro-flaking (Rots and Williamson 2004 : 1290). In addition, it is not easy to distinguish micro-flakings caused by using tools from those caused by making tools. Therefore, the frequency of micro-flaking is not always a crucial indicator to estimate the direction of tool movement of end scrapers.

To overcome this problem, the author developed an interpretative model to estimate the direction of tool movement from the viewpoint of the relationship between the use angle and the edge angle (Takase 2005). In Figure 7, the vertical axis covers

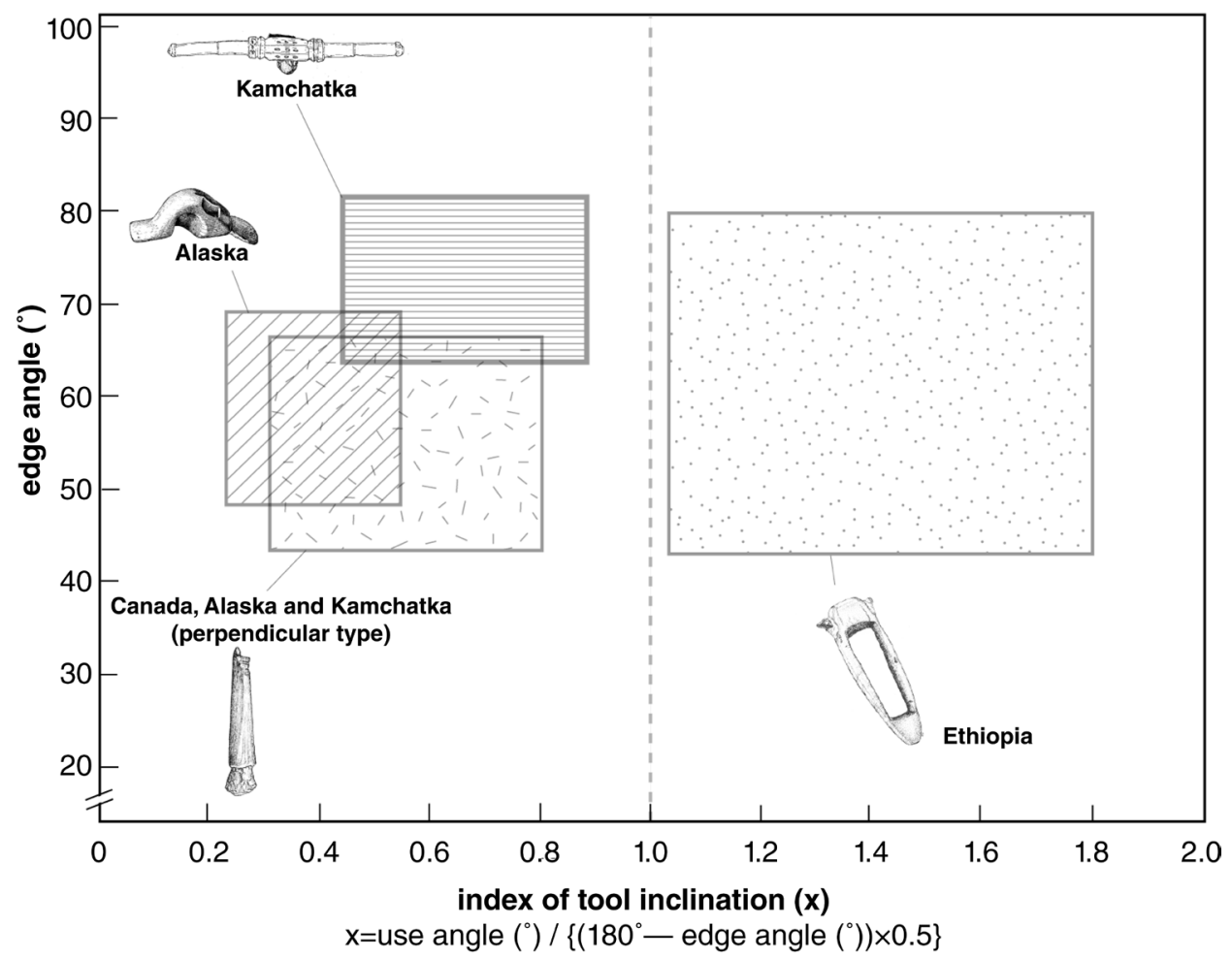

Fig. 7. A model for estimating the direction of end scraper tool movement.

Sources: Ethiopia-Clark and Kurashina 1981, Gallagher 1977; Alaska and Canada-Murdoch 1892, Nissen and Dittemore 1974; Kamchatka: Takase 2004. 
the edge angle and the transverse axis provides an index of the tool inclination of the end scraper during use. This index $(\mathrm{x})$ is calculated using the following equation:

$$
\mathrm{x}=\text { use angle }\left(^{\circ}\right) /\left\{\left(180^{\circ}-\text { edge angle }\left(^{\circ}\right)\right) \times 0.5\right\}
$$

If the index value is larger than 1.0, the end scraper is interpreted to be used in a pulling motion like that of Ethiopian tanners. In contrast, a value smaller than 1.0 suggests that the end scraper was used in a pushing motion. According to ethnographic descriptions around the Bering Strait and my own ethnoarchaeological survey in the Kamchatka Peninsula, all stone scrapers used in a pushing motion show a smaller value than 1.0 (Fig. 7). Therefore, the index has a correlation to the direction of tool movement of end scrapers used among indigenous peoples who scrape hide and skin with flaked stone tools. Referring to this model, the motional direction of prehistoric end scrapers from Northeast Asia has already been investigated (Takase 2006, 2008a, 2008b, 2008c).

Figure 8 shows the result of such an analysis of specimens from the late Palaeolithic in Hokkaido. A cross-shaped mark indicates relatively short end scrapers (under $6.0 \mathrm{~cm}$ in length) from Kashiwadai-1 and Shimaki. They were estimated to be used in both pulling and pushing motions, but the dominant direction of tool movement is a pushing motion. The edge angle of specimens used in a pulling motion tends to be higher than that of specimens used in a pushing motion.

In Figure 8, a circular mark indicates relatively long end scrapers $(6.0 \mathrm{~cm}$ and longer in length) made on flakes and blades from Kawanishi-C and Kashiwadai-1. This model suggests that they were also used in both pushing and pulling motions. The edge angle of these specimens holistically tends to be high compared with that of small end scrapers used in a pushing motion. The dominant direction of tool movement is a pushing motion.

There were at least two ways of using end scrapers in the first half of the late Palaeolithic in Hokkaido: a pulling or a pushing motion. Furthermore, end scrapers are classified into four groups from a techno-functional point of view. Group A includes specimens made on relatively short and small flakes that were used in a pulling motion. Group B contains end scrapers made on similar flakes as group A, but they were thought to have been used in a pushing motion. Group C includes tools made on a relatively large flake that were used in a pulling motion, and group D contains end scrapers made on blades or relatively long flakes that were used in a pushing motion. These results offer support for a hypothesis about utilization of Palaeolithic end scrapers in Hokkaido submitted by Kato et al. (1970), although their materials should be assigned to a younger archaeological stage than specimens examined in the present article.

Semenov (1964:87-88) pointed out that severe wear could be seen on the right part of the working edge on 80 percent of the Palaeolithic end scrapers from Europe and the Russian territory. These end scrapers were believed to have been used in a pulling motion and held with the right hand without hafting. Materials from North America are also supposed to be used in a similar way (Wilmsen 1968:157), while some archaeologists assert the possibility of hafting and another direction of tool movement should be taken into consideration (Kato et al. 1970; Shott 1995; Takase 2004; Yamanaka 1976).

Specimens in group A tend to show heavy abrasion in the middle and the left part of the working edges (Table 3). On the other hand, observation reveals a tendency 


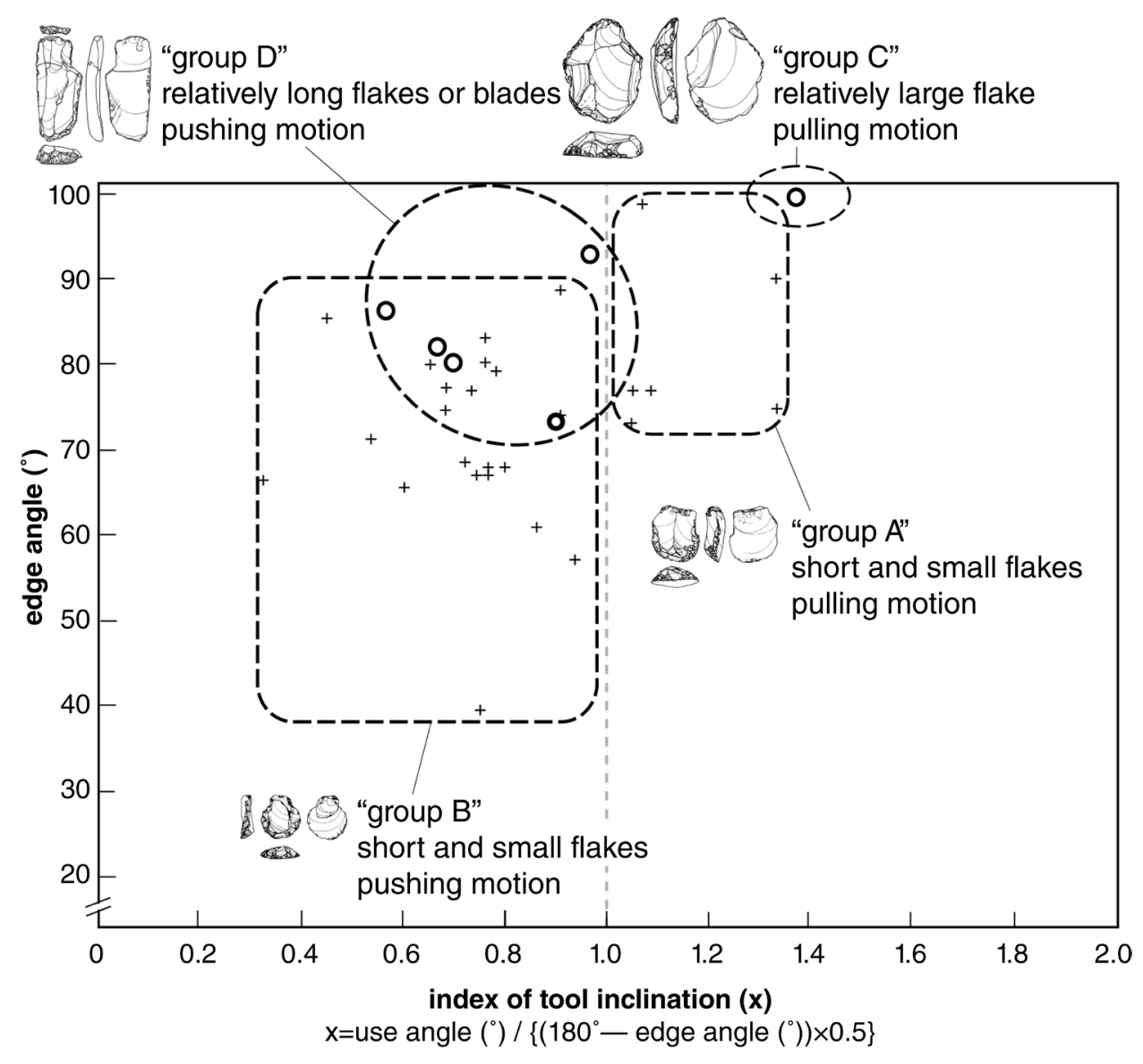

+: unifacialendscraper made on short and small flakes O: unifacial endscraper made on relatively long flakes or blades

Fig. 8. Result of estimation of the direction of tool movement.

Table 3. Part of Heavy Wear on the Working Edge Viewed from the Dorsal face LAYING THE WORKING EDGE UP

\begin{tabular}{lccccc}
\hline GROUP & LEFT & MIDDLE-LEFT & MIDDLE & MIDDLE-RIGHT & RIGHT \\
\hline A & 2 & 1 & 2 & & 1 \\
B & 6 & 2 & 8 & 1 & 4 \\
C & & 2 & 1 & 1 & 2 \\
D & & & & 1 \\
\hline
\end{tabular}

toward severe wear in various parts of the working edges of groups B, C, and D. This might be interpreted as an effect of a different grasping or hafting method. In fact, there are some specimens among group A from Shimaki with wear traces showing attachment to a wooden haft (Takase 2003). Further inspection of hafting will provide 
valuable information in the future for understanding the diverse applications of end scrapers during this period.

As mentioned above, the direction of tool movement of end scrapers had already been attempted by observations of use breakage on the working edge. However, edge damage is not always a universal sign of hide processing. The method discussed in this article has an advantage, because it is available regardless of the existence of microflaking. At the same time, its range of application is limited to specimens with heavy edge abrasion. Therefore, the results derived from the method do not necessarily apply to all end scrapers within a period.

From this point of view, combining several methods such as low- and high-power approaches of lithic use-wear analysis and techno-morphological attribute analysis will gain in importance as a means of studying end scrapers in the future. The advantages and disadvantages of each method should be recognized and taken into consideration in interpreting the results of these methodologies. Nevertheless, there is no doubt that promoting cooperation between scholars with different archaeological approaches is inevitably important in improving our examination of tool use strategies in hide production, curation systems, and reduction sequence of end scrapers.

\section{CONCLUSIONS}

The results of this study can be summarized as follows. First, we can confirm that in the first half of the late Palaeolithic in Hokkaido, end scrapers were one of the principal tools for hide-working. In addition, end scrapers were used both in a pulling and a pushing motion. Exploring further the role of scraper shape and edge angle in particular, relatively short end scrapers were used in both a pulling (group A) and a pushing motion (group B). However, among these end scrapers, a pushing motion is the dominant direction of tool movement, and the edge angle of specimens used in a pulling motion tends to be higher than that of specimens used in a pushing motion. Relatively long and large end scrapers were also used in a pulling motion (group C) and a pushing motion (group D); however in this case, pushing is the dominant direction of tool movement. The edge angle of these specimens has a tendency to be higher than that of relatively small end scrapers.

There is still no detailed traceological data for comparing this directionality of scraper use in the first half of the Palaeolithic with the succeeding period. However, it is notable that small end scraper on blade and burin became dominant in tool composition in the second half of the Palaeolithic in this region. In addition, ratio of end scrapers to the all chipped stone tools has a tendency to decrease. This fact is suggestive not only of change in hide-working technology, but also of change in the need for hide products in the society.

It is possible to make hide products using only an iron knife as described in ethnographies of the Ainu in Hokkaido. On the other hand, various tools and their diverse ways of use distinctly play an important role for making different kinds of highquality hide products using animal and fish skin among the Tungus and "Palaeoasiatic" peoples. Modern skillful hide-workers in Kamchatka tend to try to prepare a lot of instruments, with delicate differences of their tool characteristics such as plan view of stone edge, edge angle, kind of stone, and form and size of haft (Takase 2004). If the variety of tools and their use have a close relationship with social needs for hide products, it is likely that different situations appeared in the second half of the 
Palaeolithic in Hokkaido. Inspection of this estimation from the point of view of scraper and burin use is a priority for future studies.

Moreover, the methodology performed in this paper has a broad applicability to artifacts after the Jomon period, the Mesolithic, and the Neolithic; even in the modern age, this method can contribute to reveal stone scraper use and its social background. These studies lead us to an understanding of the long-term history of hide use- - one of the most important resources for human beings.

\section{ACKNOWLEDGMENTS}

I am grateful to Masahisa Yamada, Minoru Kitazawa, Toshiro Yamahara, Yusuke Kumabayashi, Irumi Sasakura, and Hiroshi Fujii for supporting my research. Their cooperation and advice were useful for me in improving the study, but the conclusions and any errors are mine alone. I would also like to thank Peter Bleed, Yuichi Nakazawa, and Masami Izuho for providing me with an opportunity to publish these early results.

\section{REFERENCES CITED}

Aкоshima, Kaoru

1989 Use-wear of Stone Tools. Tokyo: New Science Press (in Japanese).

Barnes, Alfred S.

1932 Modes of prehension of some forms of Upper Palaeolithic implements. Prehistoric Society of East Anglia Proceedings $7: 43-56$.

Bogoras, WaLdemar

1904- The Chukchee. The Jesup North Pacific Expedition, vol. VII. New York: E. J. Brill Ltd., Leiden \& 1909 G. E. Stechert.

Brandt, Steven A.

1997 The ethnoarchaeology of flaked stone tool use in southern Ethiopia, in Aspects of African Archaeology: 733-738, ed. G. Pwiti and R. Soper. Harare: University of Zimbabwe Press.

Brandt, Steven A. and Kathryn J. Weedman

1997 The ethnoarchaeology of hide working and flaked stone tool use in southern Ethiopia, in Ethiopia in Broader Perspective: 351-361, ed. K. Fukui, E. Kurimoto, and M. Shigeta. Kyoto: Shokado Book Sellers.

Brandt, Steven A., Kathryn J. Weedman, and Girma Hundie

1996 Gurage hide working, stone tool use and social identity: An ethnoarchaeological perspective, in Essays on Gurage Language and Culture: 35-51, ed. G. Hudson. Wiesbaden: HarrassowitzVerlag.

Burgess, Robert J., and Kenneth L. Kvamme

1978 A new technique for measurement of artifact angles. American Antiquity 43:482-485.

Clark, J. Desmond, and Hiro Kurashina

1981 A study of the work of a modern tanner in Ethiopia and its relevance for archaeological interpretation, in Modern Material Culture: The Archaeology of US: 303-343, ed. R. A. Gould and M. B. Schiffer. London: Academic Press.

D'Errico, Francesco

1988 The use of resin replicas for the study of lithic use-wear, in Scanning Microscopy in Archaeology: 155-167, ed. S. L. Olsen. Oxford: BAR Archaeological Series 452.

The Education Board of Chitose City

1974 Report of Excavation at Shukubai Sankakuyama Chiten. Hokkaido: Education Board of Chitose City (in Japanese).

Frink, Lisa, ANd Kathryn WeEdman, ED.

2005 Gender and Hide Production. Lanham, MD: AltaMira Press.

Fukui, Jun'ichi, AND Ken'ichiro Koshida

1999 Report of Archaeological Excavation at Kashiwadai-1 Site. Hokkaido: Hokkaido Maizobunkazai Center (in Japanese). 
Gallagher, James P.

1974 The preparation of hides with stone tools in south central Ethiopia. Journal of Ethiopian Studies $12: 177-182$.

1977 Contemporary stone tool use in Ethiopia: Implications for archaeology. Journal of Field Archaeology 4 : 407-414.

HAYDEN, BRIAN

1979 Snap, shatter, and superfractures: Use-wear of stone skin scrapers, in Lithic Use-Wear Analysis: 207-229, ed. B. Hayden. New York: Academic Press.

1990 The right rub: Hide working in high ranking households, in The Interpretative Possibilities of Microwear Studies: 89-102, ed. B. Graslund. Uppsala, Sweden: Societas-Archaeologica Upsaliensis.

1993 Investigating status with hide working use-wear: A preliminary assessment. ERAUL 50:119130.

Izuho, Masami, and Fumito Akai

2005 Geoarchaeology of Paleolithic site in Hokkaido, Japan. Kyusekki Kenkyu 1:39-55 (in Japanese with English summary).

JOCHELSON, WALDEMAR

1908 The Koryak. The Jesup North Pacific Expedition, Vol. VI. Memoirs of the American Museum of Natural History.

Kajiwara, Hiroshi, and Kaoru Akoshima

1981 An experimental study of microwear polish on shale artifacts. Kokogaku Zasshi 67(1): 1-36 (in Japanese with English summary).

KanOMATA, Yoshitaka

2003 A study of function of stone tools, in Araya Site: Report of the Second and Third Team Excavations, 1988-1989:46-54, ed. C. Serizawa and T. Suto. Niigta: Archaeology Laboratory of Tohoku University and Education Board of Kawaguchi City.

2004 A study of microblade industry from Kakuniyama site of Oishida city museum of history and folklore. Yamagata Koko 7(4): 19-32.

2008 A study of microblade industry from Kakuniyama site of Oishida city museum of history and folklore, part 2. Yamagata Koko 8(4):3-6.

Kato, Shinpei, Hiroaki Hata, and Toshiaki Tsurumaru

1970 On the endscraper: Materials from Yoshida site, Tan'no-machi, Tokoro-gun, Hokkaido. Kokogaku Zasshi 55(3): 44-74 (in Japanese with English summary).

Kato, Shinpei, and Masahisa Yamada

1988 Stone Tool Culture at Shimaki Site, Kamishihoro Town, Kato District, Hokkaido (in Japanese).

KeEley, Lawrence H.

1977 The functions of Paleolithic flint tools. Scientific American 237(5) : 108-126.

1980 Experimental Determination of Stone Tool Uses. Chicago: The University of Chicago Press.

Kitazawa, Minoru, Toshiro Yamahara, Yuko Kondo, and Testsuo Warashina

1998 Report of Archaeological Excavation at Kawanishi-C Site. Hokkaido: Education Board of Obihiro City (in Japanese).

Kitazawa, Minoru, Toshiro Yamahara, Tetsuo Warashina, Yuko Kondo, Norio Mino, Goro YAmadA, AND KuniHiKo Kigoshi

1995 Report of Archaeological Excavation at Minamimachi Site. Hokkaido: Education Board of Obihiro City (in Japanese).

Murdoch, JOHN

1893 Ethnological Results of the Point Barrow Expedition. Washington, D.C.: Smithsonian Institution Press.

NeLSON, EdWARD W.

1899 The Eskimo about Bering Strait. Washington, D.C.: Smithsonian Institution Press.

Nissen, Karen, and Margret Dittemore

1974 Ethnographic data and wear pattern analysis: A study of socketed Eskimo scrapers. Tebiwa $17: 67-87$.

Odell, George H.

1981 The mechanism of use-breakage of stone tools: Some testable hypotheses. Journal of Field Archaeology 8:197-209. 
Rots, Veerle, and Bonny S. Williamson

2004 Microwear and residue analyses in perspective: The contribution of ethnoarchaeological evidence. Journal of Archaeological Science 31:1287-1299.

Semenov, Sergei A.

1964 Prehistoric Technology: An Experimental Study of the Oldest Tools and Artifacts from Traces of Manufacture and Wear. M. W., Barnes \& Noble.

ShotT, Michael

1995 How much is a scraper? Curation, use rates, and the formation of scraper assemblages. Lithic Technology 20(1) : 53-72.

Siegel, Peter E.

1984 Functional variability within an assemblage of endscrapers. Lithic Technology 13(2):33-51.

TAKASE, KATSUNORI

2003 Use-wear on stone tools from Shimaki site, Hokkaido, in Paleolithic Culture and Lithic Use-wear Studies: Methodological Problems and Perspectives: 32-37, The Society of Lithic Use-Wear Analysis (in Japanese).

2004 Hide processing of the Even and the Koryak. Busshitsu Bunka 77:57-84 (in Japanese with English summary).

2005 Examining motional direction and use angle of scrapers, in 6th Annual Meeting of Research Association of the North Asia: 63-66 (in Japanese).

2006 Hideworking technology in Kamchatka: An ethnoarchaeological perspective, in Man in History: Socio-ethnic Processes in Micro- and Macro-history: 406-413. Russia: Kamchatka National University of Pedagogy.

2008 andscrapers of the ancient Koryak culture: A case study of the Kamchatka and Taigonos Peninsulas. Kokogaku Shukan 4:1-24 (in Japanese with English summary).

$2008 b$ Use-wear analysis of stone tools from Kamihoronai-Moi site, Hokkaido, Japan. Ronshu Oshorokko II : 49-61 (in Japanese with English summary).

2008c A study on use and function of polished axe and adzes in the first half of Epi-Jomon Period, in Chiiki to Bunka no Kokogaku: 327-344. Tokyo: Rokuichishobo (in Japanese with English summary).

2009 Research trends of hide use history: Toward interdisciplinary approach to hide resource. Nihon Kodaigaku 1:86-106. Meiji University Institute for the Ancient Studies of Japan (in Japanese with English summary).

Terasaki, Yasubumi

2006 Regional chronology of Hokkaido, in Studies in Regional Chronology of the Paleolithic: 275-314, ed. M. Anzai and H. Sato. Tokyo: Doseisha (in Japanese).

Tringham, Ruth, Glenn Cooper, George Odell, Barbara Voytek, and Anne Whitman

1974 Experimentation in the formation of edge-damage: A new approach to lithic analysis. Journal of Field Archaeology 1 : 171-196.

TSUjI, HIDEKO

1973 A report of Shimaki site, Kamishihoro, Hokkaido. Sekki Jidai 10:39-71 (in Japanese).

Tsutsumi, TAKASHI

$1997 a$ Examination of function of Araya type burins: Use-wear analysis of stone tools from Shirakusa site, Saitama Prefecture. Kyusekki Kokogaku 54:17-35 (in Japanese).

1997 A Analysis on functions of stone tools from Kashiwagayanagaosa site, in Kashiwagayanagaosa Site: 379-389. Minamiashigara City: Research Team of Kashiwagayanagaosa Site (in Japanese).

1999 Use-wear analysis of stone tools from Odai Yamamoto I site, in Archaeological Research at the Odai Yamamoto I Site: 120-125, ed. Y. Taniguchi. Tokyo: Research Team of Odai Yamamoto Site (in Japanese with English summary).

2000 Environmental adaptation by the analysis of end-scrapers in Upper Paleolithic Japan. Kokogaku Kenkyu 47(2) : 66-84 (in Japanese with English summary).

WEEDMAN, KaTHRYN

2002 On the spur of the moment. American Antiquity 67(4):731-744.

Wilmsen, Edwin N.

1968 Functional analysis of flaked stone artifacts. American Antiquity 33(2): 156-161.

YAMADA, SATORU

2006 A Study of Microblade Assemblages in Hokkaido, Japan. Tokyo: Rokuichishobo (in Japanese with English summary). 
YAMANAKA, ICHIRO

1976 Note to study the scrapers in industries of Sendoki (Japan). Shirin 59(6): 119-159 (in Japanese with French summary).

\begin{abstract}
This article examines the direction of tool movement of end scrapers used by Palaeolithic peoples for hide-working in the Japanese Islands. Specimens are approximately 400 end scrapers from three sites dated to the first half of the late Palaeolithic in Hokkaido, northern Japan. As a result of examination using a method combining the high-power approach of lithic use-wear analysis with a replication technique for measuring the edge angle and the use angle, it was clarified that end scrapers were used only for hideworking. They were classified into four groups: (1) relatively short end scrapers used in a pulling motion (group A); (2) relatively short end scrapers used in a pushing motion (group B); (3) relatively long and large end scrapers used in a pulling motion (group C); and (4) relatively long and large end scrapers used in a pushing motion (group D). Groups B and D (i.e., for pushing motion) are dominant among whole specimens. This study will contribute significantly to the investigation of tool use strategies, curation systems, and the reduction sequences of end scrapers when compared with results of techno-morphological research. At the same time, the methodology performed for this article enabled to change of needs for hide products in prehistoric society. KEYwORDs: Palaeolithic, Japan, Hokkaido, stone tools, end scrapers, lithic use-wear analysis.
\end{abstract}

